25 valves with various degrees of fibrosis and calcification. Surgical treatment of postradiation valvular disease has been reported, predominantly in patients with aortic stenosis. ${ }^{4}$ The largest surgical series for radiation-induced valvular heart disease was recently performed by Handa and associates. ${ }^{7}$ In this single-center retrospective study of 60 patients, they reported a $43 \%$ incidence of isolated aortic valve replacements.

Valvular incompetence is the most frequent hemodynamic abnormality in patients with a quadricuspid aortic valve. ${ }^{1-3}$ The occurrence of a severe aortic stenosis in the setting of a quadricuspid aortic valve is an exceptional finding and has not been reported. No such cases were recorded by Turri and colleagues ${ }^{8}$ among 140 aortic valve specimens retrieved at surgery for aortic stenosis, and Passik and colleagues ${ }^{9}$ did not mention any case of quadricuspid stenotic valve in 646 aortic valves explanted for pure stenosis. Our patient had severe aortic stenosis and coronary artery disease approximately 30 years after mediastinal irradiation for a metastatic seminoma. At operation, a calcified quadricuspid aortic valve was found characterized by a small accessory cusp between the right and noncoronary cusps which, according to Hurwitz and Roberts, ${ }^{1}$ is the most frequent variety of this malformation.

Quadricuspid aortic valves are prone to develop fibrosis, causing valve incompetence. ${ }^{3}$ In the present case, previous mediastinal irradiation is likely to have contributed to cusp calcification, allowing this malformation to develop an unusual pattern of valve dysfunction. Concomitant severe calcification of the ascending aorta and coronary artery disease indicate an extensive cardiac involvement from the effects of radiation.

\section{References}

1. Hurwitz LE, Roberts WC. Quadricuspid semilunar valves. Am J Cardiol. 1973;31:623-6.

2. Waller BF, Taliercio CP, Dickos DK, Howard J, Adlam JH, Jolly W. Rare or unusual causes of chronic, isolated, pure aortic regurgitation. Clin Cardiol. 1990;13:577-81.

3. Bortolotti U, Scioti G, Levantino M, Milano A, Nardi C, Tartarini G. Aortic valve replacement for quadricuspid aortic valve incompetence. J Heart Valve Dis. 1998;7:515-7.

4. Veeragandham RS, Golding MD. Surgical management of radiationinduced heart disease. Ann Thorac Surg. 1998;65:1014-9.

5. Brosius FC, Waller BF, Roberts WC. Analysis of 16 young (aged 15 to 33 years) necropsy patients who received over 3500 rads to the heart. Am J Med. 1981;70:519-30.

6. Veinot JP, Edwards WD. Pathology of radiation-induced heart disease: a surgical and autopsy study of 27 cases. Hum Pathol. 1996;27:766-73.

7. Handa N, McGregor CGA, Danielson GK, Daly RC, Dearani JA, Mullany CJ, et al. Valvular heart operation in patients with previous mediastinal radiation therapy. Ann Thorac Surg. 2001;71:1880-4.

8. Turri M, Thiene G, Bortolotti U, Milano A, Mazzucco A, Gallucci V. Surgical pathology of aortic valve disease. A study based on 602 specimens. Eur J Cardiothorac Surg. 1990;4:556-60.

9. Passik CS, Ackerman DM, Pluth JR, Edwards WD. Temporal changes in the causes of aortic stenosis: a surgical pathologic study of 646 cases. Mayo Clin Proc. 1987;62:119-23.

\title{
Chylous leak after cervical mediastinoscopy
}

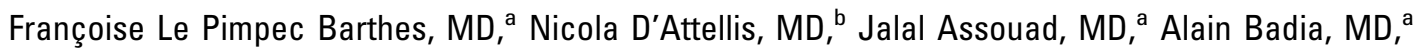 \\ Redha Souilamas, MD, and Marc Riquet, MD, PhD, ${ }^{a}$ Paris, France
}

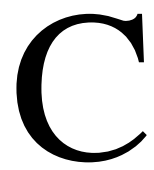

hylous leak after cervical mediastinoscopy is a rare complication. ${ }^{1}$ To our knowledge, 3 cases have been reported in the literature..$^{2-4}$ Three consecutive cases observed at our institution drew our attention to its possibly underrated occurrence.

\section{Clinical Summary}

PATIENT 1. A 16-year-old girl reported having weight loss and asthenia after an episode of erythema nodosum. On physical ex-

\footnotetext{
From Service de Chirurgie Thoracique ${ }^{\mathrm{a}}$ and Service d'Anesthésie Réanimation, ${ }^{\mathrm{b}}$ Hôpital Européen Georges Pompidou, Paris, France.

Received for publication Aug 29, 2002; accepted for publication Oct 22, 2002.

Address for reprints: Marc Riquet, MD, PhD, Service de Chirurgie Thoracique, Hôpital Européen Georges Pompidou, 20-40 rue Leblanc, 75015 Paris, France (E-mail: marc.riquet@hop.egp.ap-hop-paris.fr).

J Thorac Cardiovasc Surg 2003;126:1199-200

Copyright $\odot 2003$ by The American Association for Thoracic Surgery $0022-5223 / 2003 \$ 30.00+0$

doi:10.1016/S0022-5223(03)00799-2
}

amination, there was no lymphadenopathy or hepatomegaly. The chest radiograph demonstrated bulky paratracheal lymph nodes. Tuberculosis was suspected but could not be confirmed. Diagnosis was assessed by cervical mediastinoscopy, so as to rule out a lymphoma. During the procedure, active suction drainage of the mediastinal bed was used, yielding $300 \mathrm{~mL}$ of a milky fluid on postoperative day 1 . A chylous leak was confirmed by the presence of chylomicrons and triglycerides $(14.6 \mathrm{mmol} / \mathrm{L})$ in the fluid. Suction was discontinued, and a medium-chain triglyceride (MCT) diet was started. Lymphangiography demonstrated backflow of the contrast medium from the thoracic duct into the paratracheal lymph nodes (Figure 1). The chylous leak stopped, the mediastinum remained unchanged on successive chest radiographs, and the drain was removed on the fourth postoperative day.

PATIENT 2. A 56-year-old man had a superior vena caval obstruction syndrome. On physical examination, there was no lymphadenopathy or hepatomegaly. Chest tomodensitometry demonstrated a huge right lung tumor and large paratracheal lymph nodes. Fibrobronchoscopy failed to provide a diagnosis. A mediastinoscopy was performed. The mediastinal bed was not drained. The diagnosis of squamous cell carcinoma was confirmed. On postoperative day 3 , the mediastinoscopy incision leaked a milky 


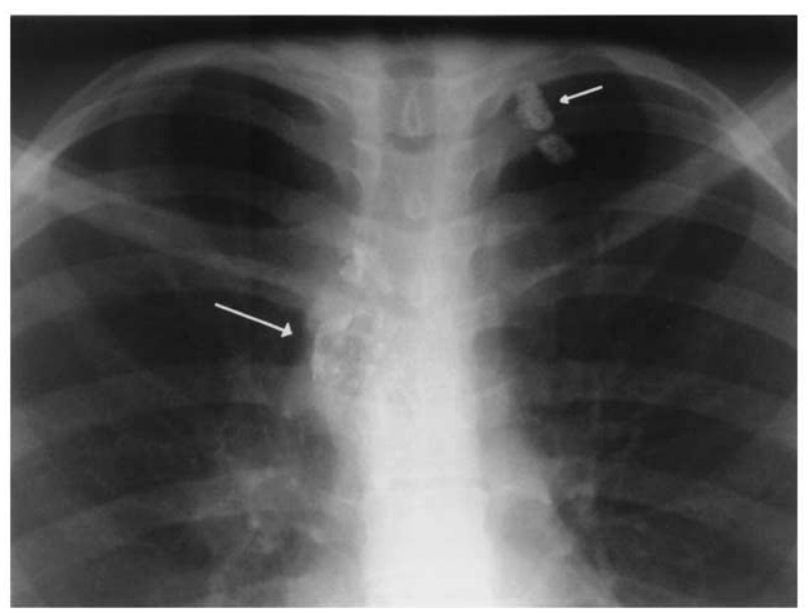

Figure 1. Lymphangiogram: paratracheal nodes are demonstrated by contrast medium backflowing from the thoracic duct.

fluid that proved to be chylous (triglycerides, $33.72 \mathrm{mmol} / \mathrm{L}$ ). An MCT diet was started. The chylous leak ceased 4 days later and never reappeared.

PATIENT 3. A 65-year-old man was admitted to our hospital because of hoarseness related to left recurrent nerve palsy. Chest radiography demonstrated a left upper lobe tumor. Tomodensitometry revealed adenopathies at the level of the aortic window and root of the left main bronchus. The results of fibrobronchoscopy were normal. A mediastinoscopy was performed, confirming the diagnosis of adenocarcinoma. Active suction drainage yielded 250 $\mathrm{mL}$ of a milky fluid on postoperative day 1. An MCT diet was started, and the chylous effusion resolved in 7 days after yielding $1500 \mathrm{~mL}$.

\section{Discussion}

The chylous leaks observed were moderate and easily controlled with conservative treatment, contrary to those reported in the English literature, which appeared to be more worrisome: in 2 cases the chylous effusion collected within the mediastinum and then ruptured into the pleural cavity, resulting in chylothorax, ${ }^{2,3}$ and in one case the leak, directly drained from the mediastinum, persisted after failure of thoracic duct ligation before being successfully managed with somatostatin. ${ }^{4}$ The fact that these 3 cases were observed consecutively in a single institution is probably coincidental but not surprising. In fact, the nodes commonly undergoing biopsy during mediastinoscopy are located along paratracheal lymphatic pathways draining the lymph from the lungs into the venous confluents of the neck. Anatomic studies ${ }^{5}$ have demonstrated lymphatic vessels joining the thoracic duct directly within the mediastinum (Figure 2) from nodes located on the right and left lower part $^{6}$ of these tracheal pathways. Such lymphatic vessels possess valves that prevent reflux of chyle from the thoracic duct. Biopsies of nodes supplied with chylum by lymph vessels with insufficient valves, as illustrated in our first case (Figure 1), might lead to a chylous leak. To our knowledge, such valve insufficiency remains unexplained and is rare. Chylous reflux within the mediastinum remains moderate because of the

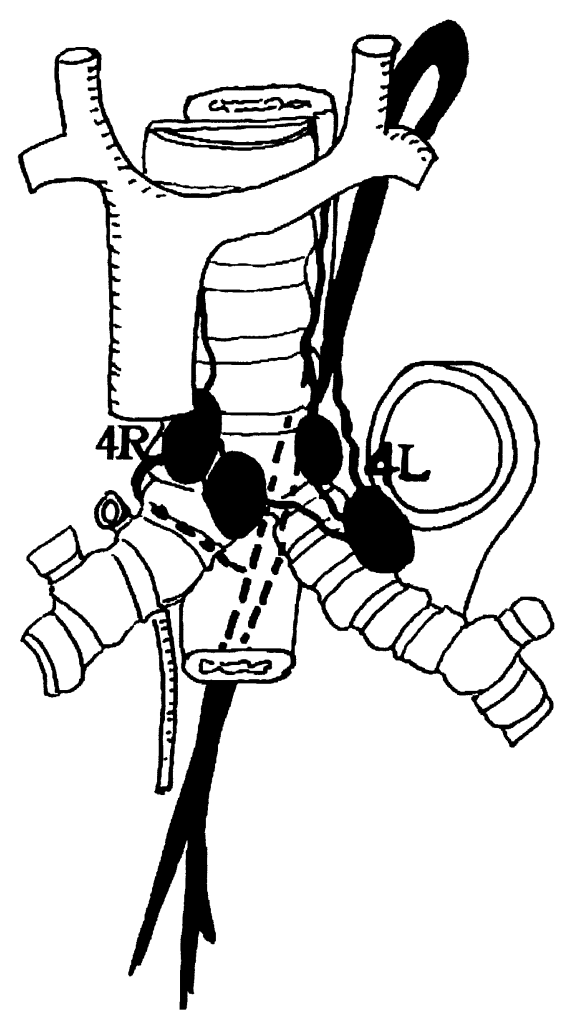

Figure 2. Location of lymph vessels connecting with the thoracic duct within the mediastinum from $4 R$ to $4 L^{6}{ }^{6}$

lymph node tissue mass, which acts as a barrier. Drainage of the mediastinal bed after mediastinoscopy is currently not performed ${ }^{1}$ and might have disclosed the chylous leak in 2 of our cases. Therefore, in most cases such moderate chylous leaks are probably restrained and plugged within the mediastinum.

We hypothesize that major chylous backflow leading to significant complications, as reported in the literature, remain rare. On the contrary, we believe that small leaks are probably not so uncommon, remaining undiagnosed because they are restrained within an undrained mediastinum. Such chylous collections are probably unknown, and their frequency is probably underreported.

\section{References}

1. Kirschner PA. Cervical mediastinoscopy. Chest Surg Clin North Am. 1996;6:1-20.

2. Kostiainer S, Menala H, Mattila S, Appelqvist P. Chylothorax. Scand J Thorac Cardiovasc Surg. 1983;17:79-83.

3. Fahimi H, Casselman FP, Mariani MA, Van Boven WJ, Knaepen PJ, Van Swieten HA. Current management of postoperative chylothorax. Ann Thorac Surg. 2001;71:448-51.

4. Collard JM, Laterre PF, Boemer F, Reynaert M, Ponlot R. Conservative treatment of post surgical lymphatic leaks with somatostatin-14. Chest. 2000;117:902-5.

5. Riquet M, Hidden G, Debesse B. The lymphatic drainage of the lungs into the thoracic duct in the mediastinum. Surg Radiol Anat. 1988;10: 165-6.

6. Mountain CF, Dresler CM. Regional lymph node classification for lung cancer staging. Chest. 1997;111:1718-23. 